\title{
A construção intencional da ignorância na contemporaneidade e o trabalho em rede para combater a desinformação
}

\author{
The intentional construction of ignorance in contemporary times and \\ networking to combat disinformation
}

\section{La construcción intencionada de la ignorancia en la actualidad y el trabajo en red para combatir la desinformación}

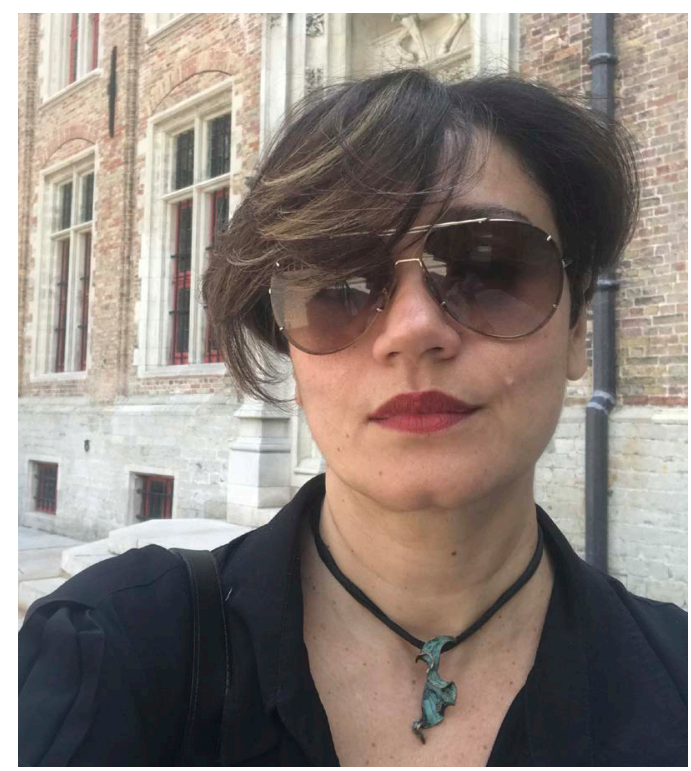

Em entrevista à Reciis, Ana Regina Rêgo aborda a problemática da desinformação na contemporaneidade, as mudanças nos regimes de verdade, o papel desempenhado pelas plataformas de redes sociais e a importância do diálogo e do trabalho em rede para combater as informações falsas. Com base nos estudos de José Correia Leite, Robert Proctor e Londa Schiebinger, a entrevistada discute a ideia da construção intencional da ignorância e o mercado das informações falsas, teses que foram trabalhadas por ela durante seu pós-doutorado na Universidade Federal do Rio de Janeiro (UFRJ). Ana Regina Rêgo é professora associada do Programa de PósGraduação em Comunicação da Universidade Federal do Piauí (PPGCOM/UFPI), idealizadora da Rede Nacional de Combate à Desinformação (RNCd) e ex-presidenta da Federação Brasileira das Associações Científicas e Acadêmicas da Comunicação (Socicom).

Palavras-chave: Desinformação; Regimes de verdade; Comunicação; Ciência; Redes sociais. 


\section{ABSTRACT}

In an interview with Reciis, Ana Regina Rêgo addresses the issue of disinformation in contemporary society, the changes in the regimes of truth, the role played by social media platforms and the importance of dialog and networking to fight false information. Building on the studies of José Correia Leite, Robert Proctor and Londa Schiebinger, she discusses the idea of intentional construction of ignorance and the false information market, topics she studied during her postdoctorate at the Federal University of Rio de Janeiro (UFRJ). Ana Regina Rêgo is an associate professor in the Graduate Program in Communication at the Federal University of Piauí (PPGCOM/UFPI), creator of the National Network to Fight disinformation (RNCd) and past president of the Brazilian Federation of Scientific and Academic Associations in the Field of Communication (Socicom).

Keywords: Disinformation; Systems of truth; Communication; Science; Social networks.

\section{RESUMEN}

En entrevista con la Reciis, Ana Regina Rêgo aborda el problema de la desinformación en la época contemporánea, los cambios en los regímenes de verdad, el papel que cumplen las plataformas de redes sociales y la importancia del diálogo y el networking para combatir la información falsa. Basada en los estudios de José Correia Leite, Robert Proctor y Londa Schiebinger, ella analiza la idea de la construcción intencional de la ignorancia y el mercado de la información falsa, tesis en las que trabajó durante su posdoctorado en la Universidad Federal de Río de Janeiro (UFRJ). Ana Regina Rêgo es profesora asociada del Programa de Posgrado en Comunicación de la Universidad Federal de Piauí (PPGCOM/UFPI), creadora de la Red Nacional para Combatir la Desinformación (RNCd) y ex presidenta de la Federación Brasileña de Asociaciones Científicas y Académicas de Comunicación (Socicom).

Palabras clave: Desinformación; Regimenes de verdad; Comunicación; Ciencia; Redes sociales. compartilhar, reutilizar e distribuir os artigos, desde que para uso não comercial e com a citação da fonte, conferindo os devidos créditos de autoria e menção à Reciis. Nesses casos, nenhuma permissão é necessária por parte dos autores ou dos editores.

\section{Reciis: Como foi a sua trajetória na pesquisa acadêmica e qual é a sua principal questão em relação à desinformação?}

Ana Regina Rêgo: Essa pergunta é bem interessante, porque normalmente quando olham para o meu currículo percebem que ele segue para várias áreas. Tenho duas questões a colocar: a primeira é que tem um fio condutor na minha pesquisa acadêmica, desde a graduação, que é a história do campo da comunicação. Isso perpassa todos os momentos da minha trajetória, desde o trabalho de conclusão de curso (TCC) da graduação até o mestrado. Isso sempre foi uma linha de pesquisa perene e constante. Tanto que atuei durante muito tempo na Associação Brasileira de Pesquisadores de História da Mídia (Alcar)i , ocupando

i O nome Alcar é homenagem ao historiador pernambucano Alfredo de Carvalho, responsável pelo inventário do primeiro centenário da imprensa brasileira. 
vários cargos da diretoria e da qual, por último, fui presidenta. Só que, mesmo quando me desloco para outra área de pesquisa, e teoricamente para outra temática, eu não me distancio da história, da historiografia ou da historicidade. E compreendo historicidade não como a trajetória histórica de algum fenômeno, mas como essência de fenômenos que têm potência histórica, pensando aqui em uma visão heideggeriana, fenomenologista (HEIDEGGER, 2015). Em relação à desinformação, vejo que esta temática está muito presente em vários momentos das minhas pesquisas, seja quando nos debruçamos sobre o jornalismo do século XIX, sobre as questões jornalísticas e a tensionalidades das crises de verdade ocidentais no Brasil durante a Primeira Guerra Mundial (1914-1918), seja quando analisamos a crise e o jornalismo brasileiro da década de 1930, ou quando pesquisamos sobre a Segunda Guerra Mundial (1939-1945), ou sobre a ditadura civil-militar (1964-1985). E, hoje, nos debruçamos sobre um fenômeno que extrapola o lugar do jornalismo, trata-se de algo que se tornou ubíquo em nossas vidas, visto que a desinformação à qual nos referimos ganha corpo e velocidade por meio da rede mundial de computadores e das mídias sociais. Por outro lado, embora pensemos que não haja desinformação no jornalismo, a trajetória da desinformação nesse campo é muito presente, e isso constitui um dos grandes motivos para a suspeição que a sociedade levanta em relação ao jornalismo, em diversos momentos da história.

Reciis: Na sua trajetória, você trabalhou e ainda trabalha com a historicidade. Como se daria a historicidade na área da desinformação?

Ana Regina Rêgo: Eu vejo a informação e a desinformação como fenômenos que se estruturam em interação direta com o fenômeno da comunicação. A desinformação, para mim, não é apenas um conceito, mas um fenômeno social, um fenômeno que existe porque existe a informação, logo a desinformação se coloca como o outro lado da informação. É algo que se "vende" como informação, por isso é aceita, pois esta é necessária à atual vida em sociedade. E a desinformação, que usa uma máscara de informação, é aceita pelos aparatos de receptividade da informação na sociedade. Uma coisa está intimamente atrelada à outra. Não há como dissociar completamente. O combate à desinformação, como nós trabalhamos, consiste em tirar o véu. Desvelar o que está silenciado, nas sombras, no não dito. É algo bem complexo e muito difícil. Por outro lado, há que se considerar que a desinformação, assim como a informação possui múltiplas dimensões que as transformam em algo fácil de ser reverberado na sociedade.

Reciis: No livro que você escreve, em parceria com a professora da UFRJ Marialva Barbosa, como o próprio título indica, vocês abordam a ideia de uma construção intencional da ignorância (RÊGO; BARBOSA, 2020). Poderia falar um pouco mais sobre isso?

Ana Regina Rêgo: A ideia da construção intencional da ignorância foi desenvolvida durante nossas pesquisas no pós-doutorado. Nós nos deparamos com um trabalho de dois autores americanos, o historiador Robert Proctor e a historiadora Londa Schiebinger, intitulado Agnotology: the making and unmaking of ignorance (2008), em que eles abordam que há, justamente, uma construção intencional de desinformação, de ignorância. Eles trazem as origens desse mercado que constrói uma certa ignorância a partir de algumas estratégias, como as de alguns cientistas que foram cooptados pela indústria do tabaco nos Estados Unidos nas décadas de 1970 e 1980. Partimos também da tese de um pesquisador brasileiro chamado José Correia Leite (2014), uma vez que ele se debruça sobre esse assunto e traz várias referências em relação a essas estratégias para minar a confiança em determinadas áreas. As estratégias vão desde a ocupação dos espaços midiáticos e de formação de opinião até a educação colocando em dúvida questões como cientificidade. Leite (2014) 
também aborda as estratégias de marketing aliadas ao jornalismo, além de outras táticas usadas há algum tempo para que se plante a dúvida, na sociedade, sobre diversas áreas da ciência.

Vale ressaltar que a dúvida, o questionamento em si, é o que motiva a ciência. Tanto é assim que quando fazemos um projeto temos que pensar sobre o que nos inquieta. Qual é o problema? A dúvida encontra-se na base da ciência. Se pensarmos sobre a idade da razão e invocarmos o cogito "penso, logo existo", de Descartes, com base na ideia de uma dúvida hiperbólica, veremos a dúvida presente. Descartes começa a duvidar de tudo o que tinha certeza, o que o leva a construir os primeiros métodos. E a partir de então nasce a cientificidade.

Já os cientistas que trabalharam para a indústria do tabaco no final do século XX e que são chamados de mercadores da dúvida, tanto por Proctor e Schiebinger (2008) quanto por Leite (2014), são exatamente esses personagens-chave, que foram cooptados pelo mercado para atuar em movimentos negacionistas da ciência, colocando-se em lugares estratégicos dojornalismo, ou agindo diretamente no processo educacional, com o objetivo de plantar a dúvida - por exemplo, plantar a dúvida de que o tabaco não causaria câncer ou de que o aquecimento global não causaria estragos no meio ambiente. Desse modo, criam-se teorias da conspiração e, ao mesmo tempo, fomenta-se a dúvida na sociedade, uma parte da qual termina por aderir a essas ideias, inclusive a de que a Terra é plana. Em 2019, 11 milhões de brasileiros acreditavam que a Terra era plana (GARCIA, 2019). Hoje, acredito que o número seja maior.

Essa construção intencional da ignorância nasce desse processo, mas na atualidade ela tem se potencializado dentro daquilo que chamamos de mercado, que atua no processo criativo de narrativas desinformacionais e que possui grandes redes de distribuição de produção de fake news, que teve seu auge no Brasil em 2020, superando, inclusive, o intenso trânsito de desinformação ocorrido no período eleitoral de 2018. As redes de comunicação por onde circulam a desinformação envolvem, potencialmente, sites e perfis nas redes sociais, além de milhares de grupos de distribuição por aplicativos de mensagens. Todavia, não podemos esquecer que parte da mídia em geral e, especificamente, alguns programas jornalísticos também se ocupam da tarefa de produzir e divulgar desinformação. Esse complexo mercado que extrapola a mentira, possui muita potência para produzir e fazer circular determinadas narrativas que podem ser chamadas de desinformacionais. É preciso destacar a complexidade das narrativas híbridas com que trabalham os mercadores que operam com desinformação. Não se trata somente de fakes, fraudes ou mentiras - essas compõem uma pequena porcentagem das informações falsas que circulam. Trata-se de narrativas dúbias e/ou híbridas, que mesclam fatos e mentiras, apresentam narrativas descontextualizadas, imprecisas e manipuladas, de modo a levar o receptor da mensagem a acreditar na desinformação, pois nela há alguma informação comprovada.

Traçamos, em nosso livro, uma trajetória desse mercado das informações falsas. Procuramos trazer uma visão crítica sobre a desinformação na Rússia de Vladimir Putin, onde há todo um aparato estatal de controle da RuNet, a internet russa. Por lá, há um incentivo governamental para que os jovens abram seus perfis e atuem em defesa do governo, mas, por outro lado, também existe um grande número de trolls em ação, conhecidos como fábrica de mentiras que usam a sátira para sensibilizar a sociedade. $\mathrm{O}$ atual governante começou com essa prática, sensibilizando a sociedade e, ao mesmo tempo, disseminando desinformação. Os trolls têm muito esse link de ser uma sátira desinformativa.

Depois, passamos para a Inglaterra, com a Cambridge Analytica. No momento em que fizemos a pesquisa, a empresa já havia sido fechada na Inglaterra por conta de todos os agravos às leis daquele país. Mas nós traçamos um caminho a partir dessa história, que segue rumo aos Estados Unidos e, depois, ao Brasil.

Embora haja muita pressão em cima das plataformas digitais por parte da sociedade, dos governos e dos congressos para que elas se tornem transparentes e retirem do ar determinados conteúdos, percebemos que atualmente esse mercado se beneficia do poder de negócio das grandes plataformas 
digitais, tais como Facebook, Instagram, Google, YouTube e Twitter. O modelo de negócios favorece a possibilidade de desinformação e esse mercado, voltado para uma moral conservadora e um retorno ao passado, lucra tanto em termos financeiros quanto políticos.

O mercado das informações falsas é bastante complexo, tem muitas nuances e se configura como um dos lados do fenômeno da desinformação. Este fenômeno possui também produtores dentro da própria sociedade, que são aqueles que trabalham com a desinformação não intencional, mas que também terminam por prejudicar a coletividade, sobretudo, em momentos como o da pandemia da Covid-19. Ambas as formas de produção de narrativas desinformacionais (intencional e não intencional) circulam pelos mesmos meios: redes sociais, aplicativos de mensagens, sites, espaços jornalísticos etc. Neste contexto, temos como 'campeões' de circulação no Brasil, os grupos de família e de religiões mais conservadoras, que se fazem presentes, sobretudo, no WhatsApp.

Reciis: Há, de fato, uma mudança no sistema de crenças da sociedade. De um regime de verdade baseado nas instituições (sobretudo, o pensar científico) passamos para outro voltado para as emoções, testemunhos e crenças. O que você pensa sobre isso? Você acha que é possível um movimento de retorno?

Ana Regina Rêgo: Sou da escola de jornalismo da Universidade Federal do Piauí (UFPI) e toda a nossa escola é voltada para o jornalismo pragmático, o modelo norte-americano. Fui ensinada a ver a verdade por métodos. Contudo, em minhas pesquisas mais recentes ou, pelo menos, há cerca de dez anos, tento desvelar a construção desse jornalismo que se forjou no paradigma do regime de historicidade da modernidade, calcado em processos e práticas que objetivavam credibilizar esse lugar de fala, tornando-o um produto credível e vendável, em cujo centro localizamos um ethos que evocava imparcialidade, objetividade e, de certo modo, um atrelamento aos métodos e à cientificidade.

Estávamos com o olhar muito fechado para o regime de verdade (FOUCAULT, 1996) pautado na evidência, que é o regime de verdade das ciências naturais, que são consideradas mais exatas (hard science), mas esse regime já foi contestado, desde o momento de sua instauração, pelo campo das ciências humanas. Tal contestação está presente em Nietzsche (2005), em Heidegger (2015), em Foucault (1996; 2008; 2011), entre tantos outros.

Esse regime, que é calcado na evidência e que pressupunha um método, foi desvelado no ambiente do jornalismo e a sociedade percebeu que o jornalismo manipulava. Falo do jornalismo porque é o nosso campo, o nosso lugar de fala. Isso é bastante complexo, mas também vem de um processo de crise e de crítica.

Ao pensarmos com Reinhart Koselleck (2009), percebemos que as críticas fazem eclodir os momentos de crise e isso provoca um processo de revisão. Pensávamos que esse regime de evidência era o único e que as sociedades se pautavam por ele, mas outros regimes coexistiam com ele. Nietzsche (2005) traz o confronto entre o moralismo religioso e a ciência. A fala de Deus que pensávamos ter perdido alguma força, sempre esteve aí. Sempre esteve latente. Então esse regime de crença, essa mística, nunca se apagou. O regime da experiência também não se extinguiu com a ciência. Recentemente, no entanto, esses outros regimes afloraram com maior força. Potencialmente, por muitas das estratégias já mencionadas, o mercado intencional da ignorância termina utilizando-se de uma construção, de uma morfologia dessas narrativas, que desconsidera a evidência, desconsidera a fatualidade, e termina por se pautar na experiência de alguém que vai ao encontro dos valores e das crenças do outro.

Trabalha-se, portanto, com esse processo de identificação e isso não é aleatório. Quando passamos a compreender a trajetória da Cambridge Analytica, das plataformas digitais e do avanço dos movimentos antidemocráticos e conservadores pelo mundo, compreendemos que há muito mais nas sombras do 
fenômeno do que podemos perceber como cidadãos comuns. O documentário O Dilema das Redes (2020) tira o véu de muita coisa: por exemplo, como é utilizada a psicologia comportamental ou como são feitos os modelos de análise das personalidades para que se saiba mais das pessoas do que elas próprias. As plataformas utilizam esses modelos psicológicos tanto para nos vender algum produto, como nos vender enquanto produtos informacionais aos anunciantes e, por fim, também para vender os próprios anunciantes. É uma troca da qual não participamos conscientemente, somos apenas produtos. Ofertamos diariamente, de bom grado, nossos conteúdos e nossos dados para as plataformas que disputam nossa atenção para poder vender cada vez mais.

Disputam audiência numa economia de atenção. Ao mesmo tempo nos encontramos em uma sociedade de controle e de recompensa. Julgamos e somos julgados ao mesmo tempo. O fato é que há uma série de debates que estão dentro dessa questão do conflito dos regimes de verdade. Será que há uma saída ou apenas um retorno ao passado resolve? Eu acredito que não. É uma saída voltar ao regime de historicidade da modernidade calcada numa cientificidade objetivista? Eu acredito que não. Eu acredito que é preciso que encontremos um meio termo. Isso pressupõe entender como esse regime de crenças, esses valores e essas experiências estão falando mais alto que a racionalidade. Isso só pode ser feito com abertura para o diálogo, que embora difícil, se coloca como o melhor caminho.

\section{Reciis: Então, a saída seria estabelecer um diálogo?}

Ana Regina Rêgo: Acredito que sim. Para tentar fazer com que as pessoas compreendam que a narrativa que elas propõem ou as questões que elas trazem não são verdadeiras e podem prejudicar a sociedade, é preciso primeiro ouvi-las, e nós jornalistas, pesquisadores, acadêmicos não estamos ouvindo muito bem. Se por um lado, as pessoas estão blindadas e só ouvem uma 'coisa', só veem uma 'coisa' e, mesmo sendo prejudicadas, elas terminam por acreditar em algo impensável, por outro, nós não estamos abertos a ouvir suas vozes. Neste sentido, acredito que o diálogo pode ser o caminho. No que concerne ao jornalismo, creio que o retorno a um método pautado em um jornalismo asséptico, imparcial, objetivo e distante não funciona mais. É preciso encontrar uma terceira via que possa devolver a credibilidade à instituição jornalística, a partir de uma maior interlocução com a sociedade que, por diversos meios, está sim pedindo ajuda.

Reciis: Vocês também abordam no livro a questão do enfraquecimento do ethos jornalístico e analisam como isso impõe reformulações e novas posições para o jornalismo. Quais caminhos você vislumbra para essa área neste novo contexto? Essa crise vai além da relação entre o jornalismo e o próprio mercado?

Ana Regina Rêgo: Em relação ao jornalismo, o modelo de negócios está em reformulação, mas ainda não vislumbro um novo caminho estabelecido. Porém, efetivamente, já se tem consciência de que o caminho anterior, de um mercado financiado, é muito complexo e faz com que as narrativas jornalísticas sejam tendenciosas do ponto de vista mercadológico e político. Acho que isso é uma coisa latente, clara, para todo profissional da área. Também acredito que é óbvio o fato de que não dá para voltar ao modelo anterior, de uma práxis, de um habitus, dentro desse campo jornalístico. Porque no atual momento, não somos apenas nós que usamos aquilo que Bourdieu (1997) chama de "óculos especial" (p. 25) do campo jornalístico. Não temos mais esse poder de filtragem, de gatekeepers especiais. Isso se diluiu na sociedade e está em diversos campos, em diversas redes, em diversos momentos. Sem falar que temos alguns dilemas, a saber: nem 
podemos retornar ao que foi o jornalismo na modernidade; nem podemos ir para um processo jornalístico anterior eminentemente opinativo e político brasileiro do século XIX, muito menos nos pautarmos nos regimes de valores e crenças da atualidade.

Acho que não é o caso de se retornar a isso, mas de entender que somos humanos, somos subjetivos e que as empresas intervêm na sociedade e sofrem intervenção da mesma. Há uma dialética nesse processo. A imparcialidade é outra questão, é um grande tabu. Tenho ouvido de algumas amigas da área da medicina: "é que o jornalismo agora é só opinião, a pessoa só fala o que quer". Como se a opinião não estivesse dentro da informação em todos os momentos. Por isso, penso que a saída talvez seja encontrar essa terceira via. Eu vejo no midialivrismo algum caminho sendo formatado. Talvez não seja o caminho definitivo, mas vejo uma negociação dentro desses campos. Primeiro, uma colocação clara de quem somos e onde nos situamos, na verdade todos os veículos sempre estiveram em algum lugar, trabalhando por algum governo ou contra, mas sempre tentaram 'mascarar' dentro de uma narrativa que se pretendia asséptica, que se pretendia imparcial. Agora o jornalismo tem se permitido aos poucos se colocar, acho que é um paradoxo, uma nova construção. E teremos que encontrar um caminho, mas isso não é só uma questão do jornalismo. É um caminho de negociação com toda a sociedade, entre esses regimes que estão em confronto.

Não há uma percepção de que a comunicação é também um processo a ser observado de um outro ângulo. Não se pensa que estamos abertos a algumas influências quando entramos em alguma rede social, vemos algum programa de televisão ou ouvimos alguma coisa. Não se pensa na comunicação como esse fenômeno que pode ser observável e analisado por uma construção e por uma via de um estudo cientificamente orientado. É uma coisa completamente naturalizada e tudo que é efetivamente muito naturalizado, como a fala de Deus ou o lugar das crenças, tem uma potência de manipulação muito grande. Há uma potência manipuladora e é difícil confrontar-se com esses processos e essas crenças todas. Então, se você está conversando, por exemplo, com uma pessoa da área da medicina, é bem provável que você não vá convencê-la de que o seu conhecimento científico sobre comunicação tem um lugar de fala superior ao dela. O melhor a fazer é recuar para ouvir e, talvez, abrir um espaço de diálogo. Acho que o principal caminho no momento é o diálogo.

\section{Reciis: Você acredita que a comunicação ainda é vista como instrumental pela sociedade? Como você acha que isso afeta e dificulta o entendimento da comunicação como ciência?}

Ana Regina Rêgo: Essa questão da compreensão da comunicação como uma ferramenta, um instrumento para se obter alguma coisa, uma determinada reação do público, não é só um entendimento da sociedade em geral. É um entendimento dentro do campo da ciência, em muitos casos até existe um consenso do que outras ciências pensam sobre o campo da comunicação

Como presidenta de associações em contato com representantes de outras associações científicas, dentro do fórum das filiadas da Sociedade Brasileira para o Progresso da Ciência (SBPC), em diversas ocasiões em debates e oportunidades, pude perceber o quanto a comunicação é vista como um meio para divulgação científica, um meio para divulgação para mídia.

Eu tenho muita dificuldade em me adaptar a uma única especialidade dentro da comunicação. Eu vejo a comunicação por redes e por fluxos, que são interagentes e que estão, ao mesmo tempo, influenciando e sendo influenciados. E dentro do campo da comunicação, há uma visão fragmentada em especialidades, que é uma tendência do processo da modernidade em detrimento de uma visão mais ampla. Como também há uma visão, no próprio campo, que prioriza questões muito mais pragmáticas e muitas vezes funcionalistas. 
Reciis: Como você avalia a atuação do campo da ciência e do jornalismo durante a pandemia? Você acha que o contexto da Covid-19 contribuiu para um resgate da valorização dos fatos científicos e jornalísticos?

Ana Regina Rêgo: Primeiro, a pandemia potencializou a circulação da desinformação, de narrativas fakes, imprecisas e manipuladas. Uma pesquisa feita pelo Reuters Institute em parceria com a Oxford University (2020) concluiu que, no que diz respeito a informações falsas, houve um incremento de $900 \%$ na Inglaterra durante os três primeiros meses da pandemia do novo coronavírus.

Enquanto coordenadora de um projeto de fact-checking, recebemos diariamente denúncias feitas pela sociedade no aplicativo Eu Fiscalizo, da Fundação Oswaldo Cruz (Fiocruz), com quem temos um convênio, e essas denúncias são narrativas que, muitas vezes, começaram na Austrália, foram descontextualizadas em algum país na Europa e terminaram no interior de São Paulo. Neste momento, estamos com uma potencialização das narrativas desinformacionais sobre as vacinas contra a Covid-19.

Para além disso, temos presenciado um confronto entre o regime de verdade da evidência científica e o regime de experiências da medicina. De um lado, os cientistas que trabalham diuturnamente para comprovar suas teses, de outro, médicos que se pautam em suas experiências de consultório ou de hospitais para prescrever tratamentos profiláticos, não comprovados pelos primeiros. Muitos desses profissionais da medicina, apesar de não estarem desenvolvendo pesquisas sobre os medicamentos que podem ou não ser usados para prevenir a doença, acreditam, por exemplo, na Ivermectina, e prescrevem esse medicamento para seus pacientes e seus vídeos circulam pela internet. Embora, eles tenham a intenção de ajudar seus pacientes, esses médicos acabam confrontando o regime de verdade da evidência científica e provocando, muitas vezes, uma desinformação em grande escala, pois esses vídeos circulam por inúmeras redes sociais. E pessoas que não são seus pacientes e podem ter comorbidades, ao visualizar os vídeos, terminam por colocar a própria saúde em risco.

Nos Estados Unidos e na Inglaterra, o conceito de desinformação (WARDLE; DERAKHSHAN, 2017) tem diferenças entre misinformation (desinformação não intencional), disinformation (intencional) e a mal-information (informação verdadeira usada dentro de um contexto que se torna desinformação). Tudo é bem potencializado e a reação da ciência e do jornalismo não poderia ser outra: é preciso comprovar, pois a vida das pessoas está em jogo. Nós temos mais de 240 mil mortos no Brasil pela Covid-19, então, é preciso se pautar pelas evidências e pela fatualidade. Devemos nos pautar por aquilo que vai se comprovando e se descartando a cada dia, mesmo enquanto a dúvida permanece em relação ao novo coronavírus e suas variantes.

Quando pensamos em Yuval Harari (2018), por exemplo; ele vai dizer que a revolução científica não é uma revolução do conhecimento, mas sim uma revolução da ignorância. Primeiro, assumimos que não sabemos; depois duvidamos e vamos atrás de novos conhecimentos. Então, a ciência tem que partir efetivamente para esse processo.

No campo das ciências humanas, em especial no campo jornalístico, isso se torna um pouco mais complexo, porque não é só ir atrás da evidência, uma vez que há uma construção das narrativas, dos fatos e das interpretações. Na realidade, a construção da narrativa não determina a interpretação, já que dentro de um processo da hermenêutica de consciência histórica (RICOEUR, 2010) é o leitor que determina, ou como diz Ricoeur (2002), “[...] não é a intenção do autor que conta, mas o que os leitores leem” (p. 30). Dentro das ciências humanas, no campo da comunicação e do jornalismo, só a fatualidade em si não resolve a dúvida da sociedade porque há um confronto de narrativas. Há uma crise desse regime.

Temos dentro das Rede Nacional de Combate à Desinformação (RNCd-Brasil), que criamos em setembro de 2020, vários projetos de fact-checking. Um deles é nosso - Nujoc Checagem. Nós temos visto atualmente 
o nascimento de agências de fact-checking que fazem parte do mercado da construção da ignorância com o objetivo de combater as agências de fact-checking, que são tidas por estas, como agências de esquerda.

Efetivamente, esse confronto entre regimes tende a permanecer se trabalharmos apenas com factchecking, se trabalharmos apenas com retorno a uma metodologia do passado e se trabalharmos apenas com valores do passado que eram usados para credibilizar a instituição jornalística. Precisamos mais do que isso para lidar com o atual fenômeno da desinformação, acredito que precisamos da humildade do jornalista, do pesquisador e do cientista, precisamos encontrar o caminho para estabelecer o diálogo.

O que buscamos entender - e, por isso, eu e Marialva (Barbosa), optamos por trabalhar com a hermenêutica da consciência histórica (RICOEUR, 2010) - é como essas narrativas chegam até as pessoas e como são interpretadas. Como cada um de nós recebe a mesma narrativa, às vezes pelo mesmo grupo de WhatsApp da família, e por que o nosso processo interpretativo é distinto? O que atua como lastro que mantenho com o passado, na interveniência da consciência do presente, enquanto consciência coletiva e histórica, enquanto formação do pensamento? Daquilo que minha memória aciona, que o meu conhecimento aciona e, ainda mais, dos meus valores e das minhas crenças, daquilo em que eu quero acreditar, o que intervém nesse meu processo de interpretação? Todas essas questões, se respondidas, podem revelar porque as pessoas se revelaram muito mais misóginas, homofóbicas, machistas, racistas etc. Que valores eram esses que estavam adormecidos? Havia no Brasil anterior todo um trabalho de trazer (não chamo de minorias porque nós mulheres não somos minoria, os negros também não são minoria) determinadas comunidades historicamente prejudicadas e injustiçadas para uma tentativa de condição de igualdade social, no que diz respeito ao direito do cidadão, mas, principalmente, à própria condição de ser. O Brasil de 2021 revela todos os nossos valores herdados de um processo de dominação histórica. É como se essa parte extremamente complexa e muito negativa estivesse ali adormecida e, ao mesmo tempo, fosse acionada por alguma narrativa, no caso, a narrativa do atual governo, que não respeita nada, nem ninguém. É exatamente o que Bourdieu (1989) chama de violência simbólica e que se revela, quando se propagam essas narrativas (misóginas, preconceituosas, racistas etc.) e elas autorizam as pessoas a manifestar seu sentimento de ódio. O mercado da construção intencional se alimenta também disso e serve para estabelecer o ódio, provocar o desentendimento político e dividir a sociedade para facilitar o processo de dominação.

\section{Reciis: Você não vê uma saída única para a desinformação?}

Ana Regina Rêgo: Não. Eu não vejo uma única saída. Não acho que o jornalismo seja a única saída. Acho que o fact-checking é um trabalho que está se fazendo necessário, mas não sozinho. O letramento para a mídia, para o jornalismo e para os conteúdos que circulam pelas redes sociais, para mim é muito importante. A divulgação científica é muito importante. A própria aproximação entre as áreas cientificas mostra essa importância.

Nós criamos a Rede Nacional de Combate à Desinformação (RNCd-Brasil) no segundo semestre de 2020 e começamos a perceber que a preocupação com a desinformação nem sempre vem acompanhada do entendimento desse fenômeno ou simplesmente da compreensão de como é um conceito complexo que não cabe em si, e que perpassa todas as áreas do conhecimento. Desde a filosofia até a imunologia encontramos projetos e pessoas comprometidas, querendo contribuir de alguma forma para minimizar as implicações desse fenômeno na nossa sociedade. A saída estratégica que eu vejo é dar as mãos e trabalhar de forma conjunta. A ideia da rede é unir forças. É pegar todo mundo que já faz algum projeto ou mantém alguma iniciativa nessa área e colocar lado a lado. Se olharmos nossos canais de visibilidade, a RNCd (www.rncd. org) não possui um público grande, mas a rede não se compõe de seus canais unicamente - ela é composta pelos canais de todos os parceiros. Assim, uma narrativa produzida por um parceiro pequeno de uma cidade 
do interior do Nordeste ou do Norte do Brasil, pode obter grande alcance quando replicada (repostada) por outros parceiros da RNCd. Começamos com 30 parceiros, hoje somos quase 100.

\section{Reciis: Como surgiu a ideia da rede? O que você já colheu de bom nesse caminho?}

Ana Regina Rêgo: A ideia surgiu quando eu fazia o pós-doutorado na Universidade Federal do Rio de Janeiro (UFRJ) em 2019. Era uma rede de monitoramento e fact-checking. Posteriormente, entrei como voluntária no projeto Mandacaru e tentei implantar a ideia por lá, mas acabou não dando muito certo. Então, eu fui atrás de minha rede de amigos e pesquisadores da comunicação, fiz contatos com o Brasil inteiro, com meus amigos e com os projetos que já temos nesta área. No próprio campo da comunicação, descobri que fact-checking não eram tantos, mas tínhamos projetos de letramento e divulgação científica. Aos poucos, amigos foram indicando projetos de outras áreas, fomos fazendo contato e atualmente temos um menu enorme no site, que faz o link com todos os canais de todos os parceiros. O site é atualizado diariamente. Nós também temos outros meios de comunicação, que é um grupo de WhatsApp e um grupo de e-mails e drives nos quais compartilhamos aquilo que cada parceiro considera importante e o que cada um quiser compartilhar.

No momento temos uma força-tarefa voltada para a questão da vacina, que está sendo intensificada. Alguns parceiros da RNCd, como a União Pró-Vacina (UPVacina) e o Observatório da Covid-19-BR, lançaram recentemente a campanha \#TodosPelasVacinas com adesão de formadores de opinião por todo o país. Cada parceiro trabalha na sua área: temos aqueles que trabalham com fact-checking diariamente, aqueles voltados para o campo da saúde e da Covid-19, outros voltados para o campo religioso, outros para o campo político e outros voltados para a questão do meio ambiente. Nós também temos diversos projetos de divulgação científica que são realizados por cientistas da imunologia, da farmácia, da infectologia, dentre outros. Temos também vários projetos de comunicação educativa que trabalham em diversas frentes tentando levar uma informação de qualidade, além de associações, instituições, museus, jornais universitários e jornais que tentam trabalhar nesse sentido.

\section{Reciis: E como é trabalhar em rede? É uma maneira de unir forças?}

Ana Regina Rêgo: Exatamente, a ideia da rede é isso: unir forças e não levar mais trabalho para ninguém. O intuito é fazer o que você já faz dentro do seu grupo de pesquisa, produzir o que você já produz dentro do seu coletivo, dentro da sua agência. É uma iniciativa pequena frente a todo esse mercado da desinformação, a todo esse fenômeno, mas é uma primeira iniciativa, podem vir outras. Neste momento, nós trabalhamos só com voluntários na própria rede e no projeto, o trabalho é muito grande e atendemos conforme nossas possibilidades. Temos projetos parceiros vinculados a instituições como Fundação Oswaldo Cruz (Fiocruz), Universidade de São Paulo (USP), Universidade Federal do Piauí (UFPI), Universidade Federal de Pernambuco (UFPE), Universidade Federal do Rio Grande do Norte (UFRN), Universidade Federal do Tocantins (UFT), Universidade Federal da Paraíba (UFPB) e outros. São inúmeras instituições públicas, sobretudo federais, e algumas privadas. Unir todos em prol de um objetivo comum tem sido gratificante e tem quebrado muitos paradigmas. 


\section{Reciis: Já teve algum feedback sobre o trabalho?}

Ana Regina Rêgo: Temos recebido feedback, as pessoas gostam muito da proposta. Há uma adesão muito boa. Tivemos mais de 60 novos parceiros desde o lançamento. Temos colhido algumas vitórias relacionadas a um trabalho coordenado, sobretudo frente ao movimento antivacina. Temos tido uma boa visibilidade, no sentido de trabalhar com várias instituições temáticas no Brasil e no exterior, mas acho que o trabalho ainda está engatinhando. Estamos começando e ainda temos muito potencial para ser desenvolvido. Acho que, de alguma forma, vamos ter que profissionalizar o relacionamento com as próprias plataformas que criticamos para que possamos trabalhar efetivamente nesse combate à desinformação. Não sei exatamente que estratégia usaremos, mas acredito que temos muita potência e o trabalho está apenas começando.

\section{Reciis: Você tem algo mais a acrescentar?}

Ana Regina Rêgo: Em relação ao livro A construção intencional da ignorância: o mercado das informações falsas (RÊGO; BARBOSA, 2020), não foi nosso primeiro trabalho sobre desinformação, porque do ponto de vista histórico temos vários artigos publicados em livros e revistas, entre outros meios impressos ou eletrônicos. Em relação ao fenômeno atual da desinformação, foi um primeiro trabalho que se desdobrou em outros, durante 2020, tanto no próprio campo da práxis com a rede, quanto no universo acadêmico. Avançamos em relação a uma série coisas que estão no livro e em outras tantas que foram surgindo por conta da pandemia, questões que futuramente podem se transformar em algumas contribuições ao campo. Tem muita gente boa pesquisando, há pesquisas excelentes no Brasil e no exterior e procuramos manter uma interlocução com todas e todos. É o diálogo que nos permite crescer e contribuir mais.

\section{REFERÊNCIAS}

BOURDIEU, Pierre. Sobre a Televisão. Rio de Janeiro: Jorge Zahar Editor, 1997.

BOURDIEU, Pierre. O poder simbólico. Rio de Janeiro: Bertrand Brasil, 1989.

FOUCAULT, Michel. Microfísica do poder. 27. ed. São Paulo: Graal, 1996.

FOUCAULT, Michel. Ditos e Escritos II: arqueologia das ciências e história dos sistemas de pensamento. Rio de Janeiro: Forense Universitária, 2008.

FOUCAULT, Michel. A coragem de verdade. São Paulo: Martins Fontes, 2011.

GARCIA, Rafael. 7\% dos brasileiros afirmam que a Terra é plana, mostra pesquisa. Folha de S.Paulo, São Paulo, 14 jul. 2019. Ciência. Disponível em: https://www1.folha.uol.com.br/ciencia/2019/07/7-dosbrasileiros-afirmam-que-terra-e-plana-mostra-pesquisa.shtml. Acesso em: 20 jan. 2021.

KOSELLECK, Reinhart. Crítica e crise. Rio de Janeiro: Contraponto, 2009.

HARARI, Yuval Noah. Sapiens: uma breve história da humanidade. Porto Alegre: L \& PM Editores, 2018.

HEIDEGGER, Martin. Ser e tempo. 10. ed. Petrópolis: Vozes, 2015.

LEITE, José Correia. Controvérsias científicas ou negação da ciência? A agnotologia e a ciência do clima. Scientiae Studia, São Paulo, v. 12, n. 1, p. 179-89, 2014. DOI: https://doi.org/10.1590/S167831662014000100009. Disponível em: https://www.scielo.br/pdf/ss/v12n1/09.pdf. Acesso em: 20 jan. 2021.

NIETZSCHE, Friedrich. Além do bem e do mal. São Paulo: Companhia das Letras, 2005. 
O DILEMA das redes. Direção de Jeff Orlowski. EUA: Netflix, 2020. 1 vídeo (94 min.). Disponível em: https://www.netflix.com/br/title/81254224. Acesso em: 20 jan. 2021.

PROCTOR, Robert; SCHIEBINGER, Londa (ed.). Agnotology: the making and unmaking of ignorance. Stanford: Stanford University Press, 2008. E-book. Disponível em: https://www.sup.org/books/ title/?id=11232. Acesso em: 20 jan. 2021.

REDE NACIONAL DE COMBATE À DESINFORMAÇÃO(RNCd). Site oficial. [S. I.], 2020. Acesso em: https://rncd.orgl. Acesso em: 20 jan. 2021.

RÊGO, Ana Regina; BARBOSA, Marialva. A construção intencional da ignorância: o mercado das informações falsas. Rio de Janeiro: Mauad X, 2020.

REUTERS INSTITUTE (Reino Unido). Types, sources and claims of Covid-19 misinformation.

Oxford, Reino Unido, 2020. Disponível em: https://reutersinstitute.politics.ox.ac.uk/types-sources-andclaims-covid-19-misinformation. Acesso em: 20 jan. 2021.

RICOEUR, Paul. Tempo e narrativa. São Paulo: Martins Fontes, 2010. 3 v.

RICOUER, Paul. O único e o singular. São Paulo: Ed.UNESP, 2002.

WARDLE, Claire; DERAKHSHAN, Hossein. Information Disorder: Toward an interdisciplinar framework for research and policy making. Council of Europe Report, 2017. E-book. Disponível em: https://rm.coe. int/information-disorder-toward-an-interdisciplinary-framework-for-researc/168076277c. Acesso em: 20 jan. 2021. 